\title{
A CLINICAL STUDY OF OTORHINOLARYNGOLOGICAL SYMPTOMS IN PREGNANCY
}

\author{
Praveen Kumar' 1 , T. M. Nagraj', Joshna B. M³, Sachin S. Nair 4
}

1 Professor, Department of ENT and HNS, Rajarajeswari Medical College and Hospital, Bangalore, Karnataka, India. 2Professor and HOD, Department of ENT and HNS, Rajarajeswari Medical College and Hospital, Bangalore, Karnataka, India. ${ }^{3}$ Senior Resident, Department of ENT and HNS, Rajarajeswari Medical College and Hospital, Bangalore, Karnataka, India. ${ }^{4} J$ unior Resident, Department of ENT and HNS, Rajarajeswari Medical College and Hospital, Bangalore, Karnataka, India.

\section{ABSTRACT}

\section{BACKGROUND}

Pregnancy is a period in women's life which needs special consideration in regard to healthcare of both the mother and the foetus. ENT symptoms have an impact on the quality of life during pregnancy. Our study is to create awareness among the medical professionals to diagnose and treat the ENT symptoms in pregnancy.

Aim- To clinically evaluate the otorhinolaryngological symptoms in pregnant women.

\section{MATERIALS \& METHODS}

This is a descriptive study of 150 pregnant patients with ENT symptoms carried out in the departments of ENT-HNS and OBG of Rajarajeswari Medical College from November 2015 to June 2017.

\section{RESULTS}

$42 \%$ of study cases had ear symptoms in which, ear ache and ear fullness were mostly seen during the first trimester. Totally $46 \%$ patients presented with nasal symptoms, among which Rhinitis of Pregnancy was the main cause (24\%), predominantly observed during third trimester. $18 \%$ of the study population presented with throat symptoms, among which, $7.3 \%$ accounted to GERD, more during and after second trimester.

\section{CONCLUSION}

In our study, nasal block being the main symptom, owing to Rhinitis of Pregnancy had a significant occurrence in the third trimester. In the ear, otomycosis was the main aetiology for ear symptoms. GERD/LPR was the cause for throat symptoms.

\section{KEY WORDS}

Pregnancy, ENT Symptoms, Pregnancy Induced Rhinitis.

HOW TO CITE THIS ARTICLE: Kumar P, Nagraj TM, Joshna BM, et al. A clinical study of otorhinolaryngological symptoms in pregnancy. J. Evolution Med. Dent. Sci. 2018;7(44):4721-4726, DOI: 10.14260/jemds/2018/1054

\section{BACKGROUND}

Pregnancy is a period in women's life which needs special consideration in regard to healthcare of both the mother and the foetus. The hormonal system of women is unique especially during pregnancy, menstrual cycle and menopause. Every organ system including ENT undergoes noticeable changes during pregnancy with metabolic, endocrinologic and physiological alterations. ${ }^{1}$

Many of these changes lead to symptomatology referable to ENT as well. Thus, it is important for the otorhinolaryngologist to be familiar with the physiological changes associated with pregnancy and how these changes are manifested in Otolaryngology. ${ }^{2}$ Any medical or emotional issues during this phase will affect both the mother and the child. ENT symptoms are neglected in the regular antenatal check-up as it might not seem to pose a threat to pregnancy. Nevertheless, ENT diseases have an impact on the quality of life during pregnancy.

'Financial or Other Competing Interest': None.

Submission 17-09-2018, Peer Review 13-10-2018,

Acceptance 20-10-2018, Published 29-10-2018.

Corresponding Author:

Dr. Praveen Kumar,

\#5/6, Anugraha,

Near S. T. Peter School, Nagadevanahalli,

Bangalore South, Bangalore Viswavidyalaya-560056,

Karnataka, India.

E-mail: praveendrkumar@gmail.com

DOI: $10.14260 /$ jemds $/ 2018 / 1054$

\section{(c) $($ ) $\$$}

Our study is to help improve the same by creating awareness among the medical professionals to diagnose and treat the ENT symptoms at the earliest.

Hence, this study is being conducted to find the incidence of Otorhinolaryngology symptoms in pregnancy at our institute.

\section{MATERIALS AND METHODS}

A descriptive study of patients attending the departments of ENT-HNS and OBG in Our Institute from November 2015 to June 2017 were assessed. Those who satisfy the inclusion and exclusion criteria and were willing to participate in the study were selected. The inclusion criteria were as followsconfirmed and uncomplicated pregnancy, pregnant women with otorhinolaryngological symptoms irrespective of trimesters. Patient who had pre-existing ENT diseases such as old CSOM, allergic rhinitis, polyp etc. were excluded.

Informed written consent was taken from the patient following which detailed history was obtained and physical examination was done. Depending on the history and examination, relevant investigations were done. Followup till the third trimester was carried out in each patient and trimester wise ENT symptomatology were noted. Descriptive and inferential statistical analysis was carried out in the present study. Results on continuous measurements are presented on Mean \pm SD (Min-Max) and results on categorical measurements presented in Number (\%). Significance was assessed at $5 \%$ level of significance. 


\section{Study Design}

A descriptive study of patients attending the department of ENT-HNS and OBG in our institute Rajarajeswari medical college and hospital.

\section{Statistical Methods}

Descriptive and inferential statistical analysis has been carried out in the present study. Results on continuous measurements are presented on Mean ? SD (Min-Max) and results on categorical measurements are presented in Number (\%). Significance is assessed at 5\% level of significance. Chi-square/ Fisher Exact test has been used to find the significance of study parameters on categorical scale between two or more groups, Non-parametric setting for Qualitative data analysis. Fisher exact test used when cell samples are very small.

\section{RESULTS}

During the period of study, 150 patients presented to us with different ENT symptoms. The age of our patients varied from 15 years to 39 years. The mean age of our patients was 25.19 with standard deviation of \pm 3.74 years. In our study, $67.3 \%$ of cases were primigravida, $30.7 \%$ were of second gravida. Only $2 \%$ were of third gravida and trimester wise distribution of the patients did not show much difference. Among 150 patients, 63 presented with ear symptoms, 69 with nasal symptoms and 27 with throat symptoms.

Among 150 patients, 63 presented with ear symptoms with majority of them complaining of earache or ear fullness. Out of 13 patients who presented with earache, 7 of them were diagnosed to be otitis externa, 2 of them had AOM, 3 had otomycosis and one had impacted wax. Ear fullness/ ear block was present in 12 patients, out of which, 5 had Eustachian tube dysfunction, 4 had otomycosis, 2 had otitis externa and 1 had impacted wax. 9 patients presented with Hearing loss, among which, 6 had SNHL (pregnancy related physiological inner ear changes), 2 had CHL owing to CSOM and 1 had mixed hearing loss which was due to serous otitis media.

Ear discharge was the presenting complaint in 9 cases, among which 4 had CSOM, 3 had ASOM, 2 had otomycosis. 5 of the patients who presented with itching in the ear had otomycosis and 1 had earwax and 2 were of neurologic cause. 6 patients presented with tinnitus with no other associated ear symptoms and 6 presented to us with giddiness owing to physiological changes in inner ear during pregnancy. We observed that among the $42 \%$ who had ear symptoms, ear ache and ear fullness were mostly seen during the first trimester, whereas hearing loss and ear discharge symptoms occurred during second trimester. Tinnitus occurred in both $2^{\text {nd }}$ and $3^{\text {rd }}$ trimester while giddiness occurred mostly in first and second trimester.

In our study, 69 of the cases had nasal symptoms, nasal block was the main symptom amounting to $14 \%$, i.e., 21 patients, among them, 12 had rhinitis features, 2 had B/L inferior turbinate hypertrophy, 4 had deviated nasal septum and 3 has acute sinusitis features. Next common symptom was headache with 16 patients affected. 5 of these patients had rhinitis features, 4 had sinusitis features clinically, 2 patients had migraine, 1 had cluster headache features and due to stress induced.

Nasal discharge was the presenting complaint in 15 cases, out of which 8 had pregnancy induced rhinitis, 4 had acute sinusitis, 2 had acute rhinitis and 1 had new onset of allergic rhinitis. 11 of the cases in our study presenting with epistaxis, 9 of them had pregnancy induced rhinitis, 2 were due to pyogenic granuloma and 1 was due to nasal septal haemangioma. Decreased smell sensation amounted to 6 of the nasal symptom cases which had no other associated clinical signs, hence amounting to pregnancy related changes as it resolved as the pregnancy progressed to term period.

In our study, totally $46 \%$ patients presented with nasal symptoms, among which Rhinitis of pregnancy is the main cause amounting to $24 \%$ of the total cases, presenting as nasal block, rhinorrhoea and epistaxis which was mainly observed during third trimester.

Throat symptoms were seen in 27 of the patients in this study. The most common throat symptom was throat pain which accounted for 11 cases. Acute pharyngitis, acute tonsillitis and laryngopharyngeal reflux were present in 3 each and aphthous ulcers were the cause of throat pain in 2 cases. One patient had itching in the throat on presentation in the first trimester which later progressed to a sore throat.

Dysphagia was seen in 6 patients, 4 of them had GERD features whereas 2 of them had sideropenic dysphagia (Anaemia). A variant of this symptom was foreign body sensation. There were 7 patients who presented with this symptom, 4 had GERD, another had a fishbone impaction in right tonsil and one was considered to be a psychological cause.

Dysphonia was seen in 2 patients which can be amounted to laryngopathia gravidarum.

Only $18 \%$ of the study population presented with one of the symptoms, i.e., throat pain, difficulty in swallowing, foreign body sensation, itching in throat and change in voice. $7.3 \%$ accounted these symptoms to GERD or its variant LPR which was more during and after second trimester.

\section{Ear}

\begin{tabular}{||l|c|c|c|c|c||}
\hline \multirow{2}{*}{ EAR } & \multicolumn{3}{|c|}{ Trimester } & \multirow{2}{*}{$\begin{array}{c}\text { Total } \\
(\mathbf{n = 1 5 0 )}\end{array}$} & \multirow{2}{*}{ P value } \\
\cline { 2 - 4 } & $\begin{array}{c}\mathbf{1} \\
(\mathbf{n = 4 9 )}\end{array}$ & $\begin{array}{c}\mathbf{2} \\
(\mathbf{n = 5 4 )}\end{array}$ & $\begin{array}{c}\mathbf{3} \\
(\mathbf{n = 4 7 )}\end{array}$ & \\
\hline Ear ache & $8(16.3 \%)$ & $4(7.4 \%)$ & $1(2.1 \%)$ & $13(8.7 \%)$ & $0.041^{*}$ \\
\hline Ear fullness & $7(14.3 \%)$ & $3(5.6 \%)$ & $2(4.3 \%)$ & $12(8 \%)$ & 0.192 \\
\hline Hearing loss & $2(4.1 \%)$ & $5(9.3 \%)$ & $2(4.3 \%)$ & $9(6 \%)$ & 0.515 \\
\hline Ear discharge & $3(6.1 \%)$ & $4(7.4 \%)$ & $2(4.3 \%)$ & $9(6 \%)$ & 0.911 \\
\hline Itching & $3(6.1 \%)$ & $3(5.6 \%)$ & $2(4.3 \%)$ & $8(5.3 \%)$ & 1.000 \\
\hline Tinnitus & $0(0 \%)$ & $3(5.6 \%)$ & $3(6.4 \%)$ & $6(4 \%)$ & 0.218 \\
\hline Giddiness & $3(6.1 \%)$ & $3(5.6 \%)$ & $0(0 \%)$ & $6(4 \%)$ & 0.250 \\
\hline \multicolumn{7}{|l|}{ Chi-Square/Fisher Exact Test } \\
\hline
\end{tabular}


Nose

\begin{tabular}{|l|c|c|c|c|c|}
\hline \multirow{2}{*}{ Nose } & \multicolumn{3}{c|}{ Trimester } & \multirow{2}{*}{$\begin{array}{c}\text { Total } \\
(\mathbf{n = 1 5 0 )}\end{array}$} & \multirow{2}{*}{ P value } \\
\cline { 2 - 6 } & $\mathbf{1}$ & $\mathbf{2}$ & $\mathbf{3}$ \\
$(\mathbf{n = 4 9 )}$ & $\mathbf{( n = 5 4 )}$ & $\mathbf{n = 4 7 )}$ & & \\
\hline Nasal block & $6(12.2 \%)$ & $3(5.6 \%)$ & $12(25.5 \%)$ & $21(14 \%)$ & $0.014^{*}$ \\
\hline Discharge & $5(10.2 \%)$ & $7(13 \%)$ & $3(6.4 \%)$ & $15(10 \%)$ & 0.585 \\
\hline Nasal bleeding & $2(4.1 \%)$ & $2(3.7 \%)$ & $7(14.9 \%)$ & $11(7.3 \%)$ & $0.074+$ \\
\hline $\begin{array}{l}\text { Decreased/absent smell } \\
\text { sensation }\end{array}$ & $2(4.1 \%)$ & $1(1.9 \%)$ & $3(6.4 \%)$ & $6(4 \%)$ & 0.444 \\
\hline Headache & $4(8.2 \%)$ & $7(13 \%)$ & $5(10.6 \%)$ & $16(10.7 \%)$ & 0.733 \\
\hline
\end{tabular}

Throat

\begin{tabular}{||c|c|c|c|c|c|}
\hline \multirow{2}{*}{\multicolumn{1}{|c|}{ Throat }} & \multicolumn{3}{|c|}{ Trimester } & \multirow{2}{*}{ Total } & \multirow{2}{*}{ P value } \\
\cline { 2 - 4 } & $\mathbf{1}$ & $\mathbf{2}$ & $\mathbf{3}$ & \\
& $\mathbf{( n = 4 9 )}$ & $\mathbf{( n = 5 4 )}$ & $\mathbf{( n = 4 7 )}$ & & \\
\hline Throat pain & $2(4.1 \%)$ & $8(14.8 \%)$ & $1(2.1 \%)$ & $11(7.3 \%)$ & $0.046^{*}$ \\
\hline Dysphasia & $1(2 \%)$ & $1(1.9 \%)$ & $4(8.5 \%)$ & $6(4 \%)$ & 0.283 \\
\hline
\end{tabular}

Chi-Square/Fisher Exact Test.

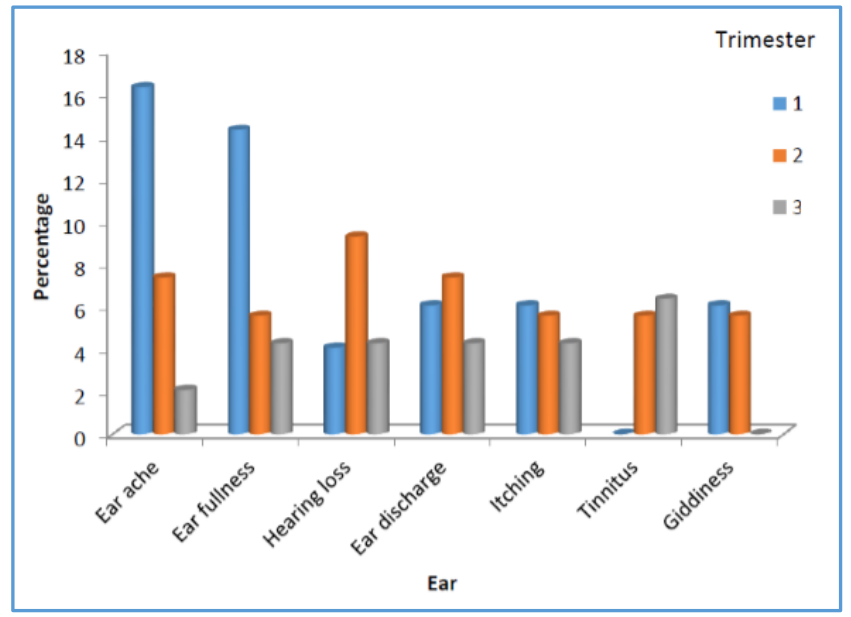

Trimester Wise Distribution of Ear Symptoms

Chi-Square/Fisher Exact Test.

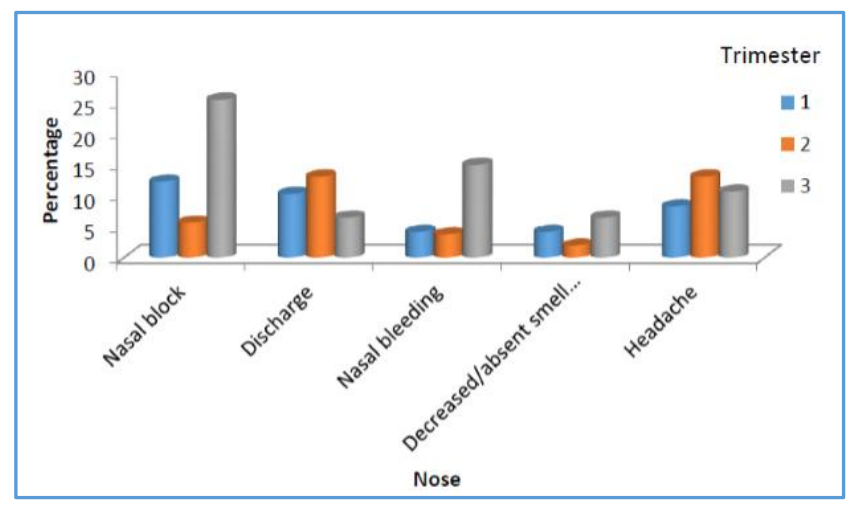

Graphical Representation of Trimester Wise Distribution of Nose Findings
Chi-Square/Fisher Exact Test.

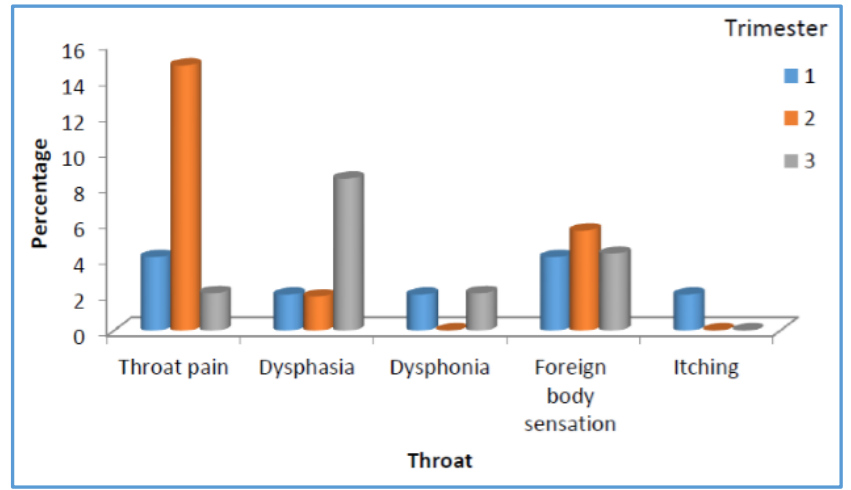

Graphical Representation of Trimester Wise Distribution of Throat Symptoms

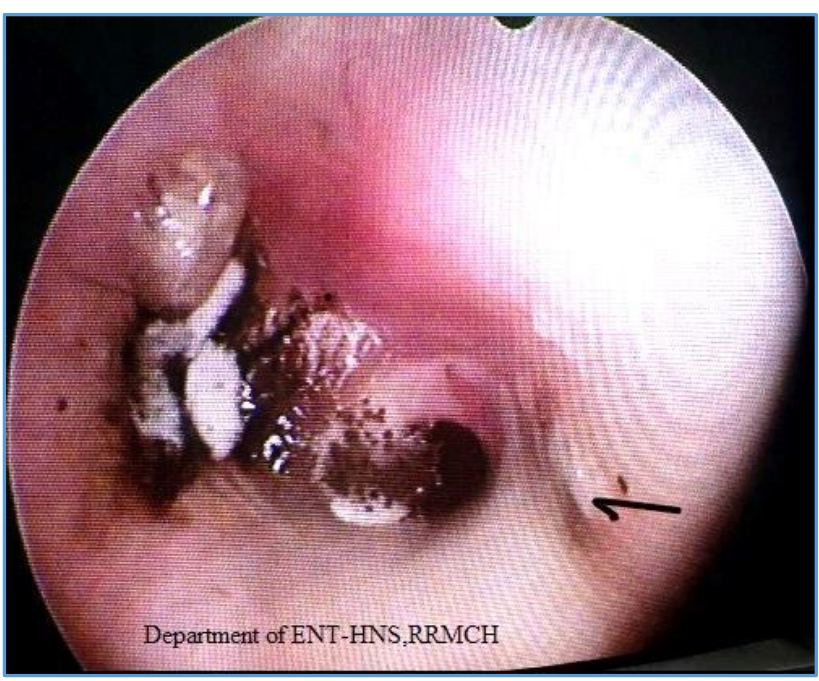

Figure 1. A Case of Otomycosis 


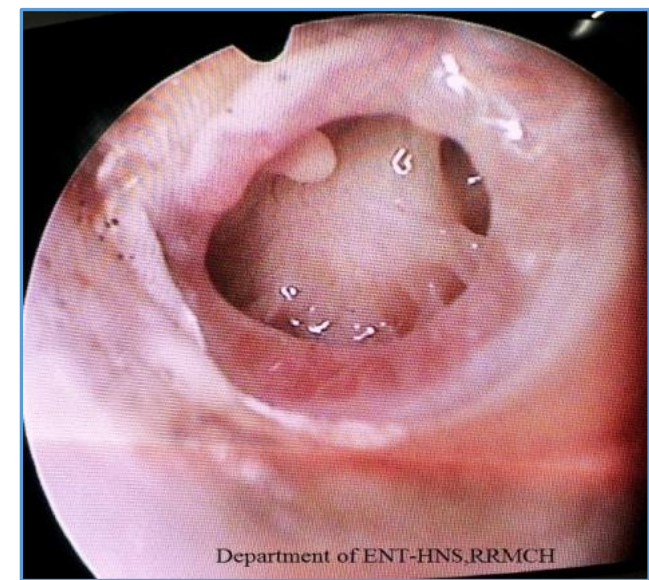

Figure 2. A Case of New Onset CSOM

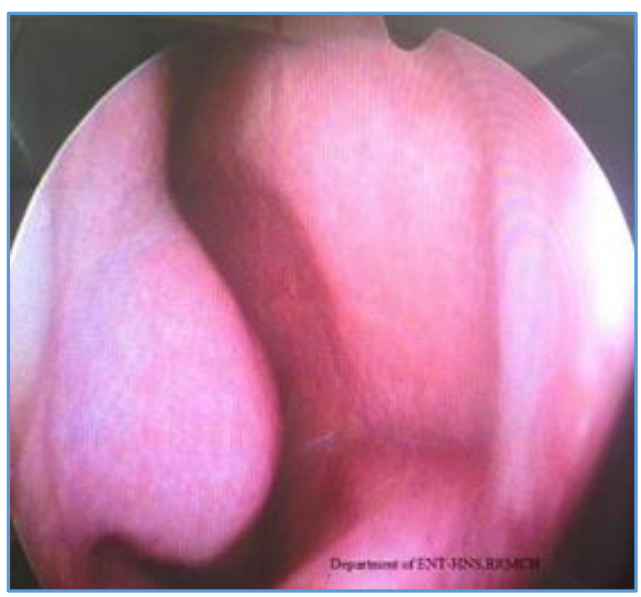

Figure 3. A Case of Symptomatic DNS and Spur to Left

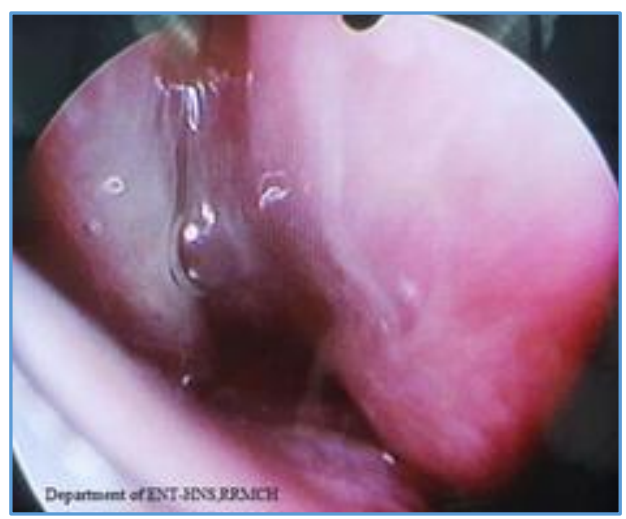

Figure 4. A Case of Rhinitis of Pregnancy

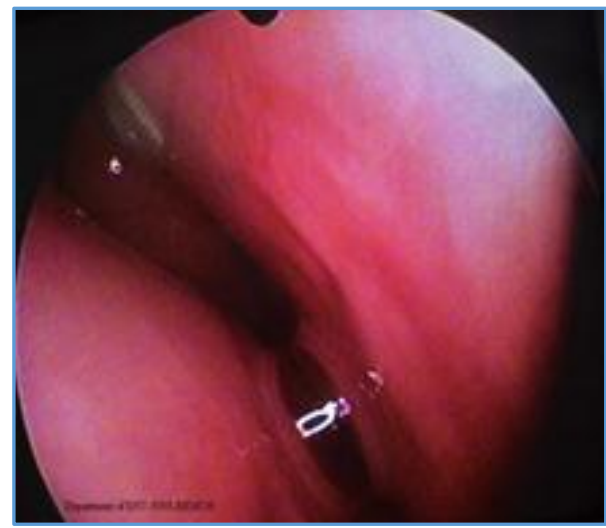

Figure 5. A Case of Rhinitis of Pregnancy

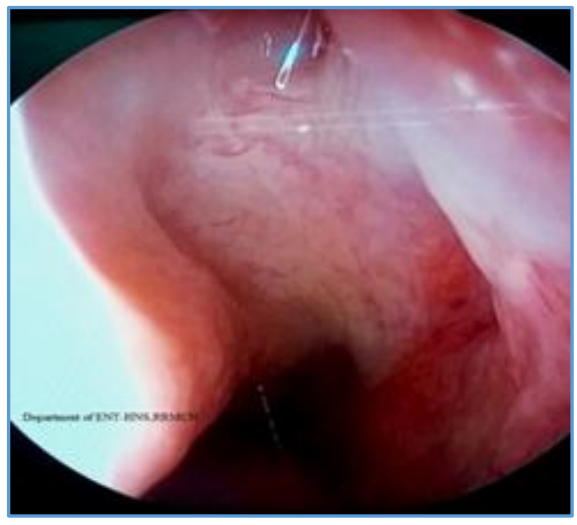

Figure 6. A Case of Epistaxis

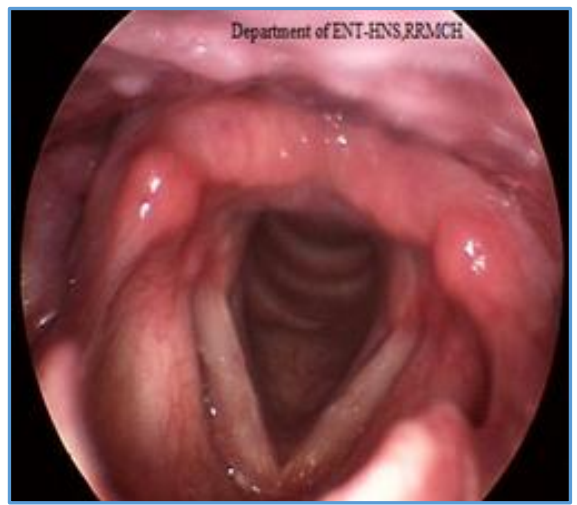

Figure 7. A Case of LPR

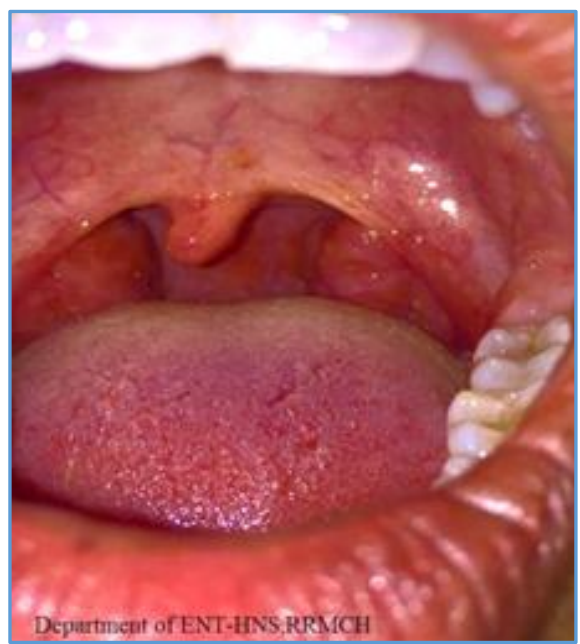

Figure 8. A Case of Acute Tonsillitis

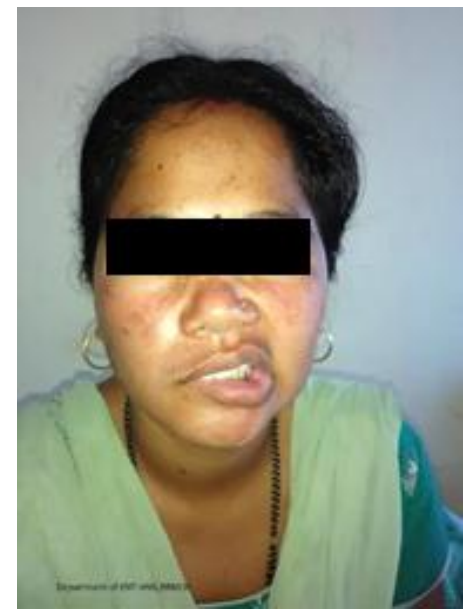

Figure 9. Right Sided Bell's Palsy 


\section{DISCUSSION}

A woman should be physically and mentally fit to walk through the challenging phase of pregnancy. Any medical or emotional issues during this phase will affect both the mother and the child. The physiological changes which occur during pregnancy has an impact on ear, nose and throat as well. When these symptoms are recognised and diagnosed in an earlier stage, the apprehensions of the pregnant woman and the distress she undergoes can be minimised.

\section{Ear}

Ear ache and ear discharge were the major ear symptoms presented in our study. Otitis externa, Acute otitis externa, acute otitis media, otomycosis, CSOM were the causes for the above symptoms. This can be owed to the fact that there is suppression of humoral and cell mediated immunological functions in order to accommodate the "foreign" semi allogeneic foetal graft. ${ }^{3}$

Eustachian tube dysfunction were seen in 6 patients who presented to us with ear fullness or ear block.

Hearing loss is another entity causing distress in pregnant women. Majority of hearing loss patients had SNHL, sudden onset was seen in 5 patients, where as one had gradual onset; SNHL did not have any other contributing factors and it recovered to near normal levels, hence concluded to be due to physiological changes in the inner ear during pregnancy. Lower frequencies such as $100,250,500 \mathrm{hz}$ were affected in these patients which persisted till the third trimester. 2 had Conductive hearing loss due to infective pathology and serous otitis media. Conductive hearing loss patients had 500, 1000 $\mathrm{Hz}$ hearing loss which recovered after the cause was treated.

Tinnitus in pregnancy is a proven entity known to be caused due to physiological changes. $16 \%$ of our study cases presented with ringing sensation in bilateral ears for which no other clinical cause was accountable. J.E Haves et al state that tinnitus might be due to hyperdynamic circulation, increase in perilymph fluid pressure and hormonal changes. ${ }^{4}$

Giddiness was not a common symptom in our study, but 12 patients did report it during second and third trimester. Attacks of vertigo is thought to be due to decline in the serum osmolality during pregnancy. ${ }^{1}$

\section{Nose}

Nose is known to be affected the most during pregnancy. In our study, totally $46 \%$ patients presented with nasal symptoms, among which Rhinitis of pregnancy or Pregnancy induced rhinitis is the main cause amounting to $24 \%$ of the total cases, presenting as nasal block, rhinorrhoea and epistaxis.

Philott et all concluded in their study that the effect of pregnancy on nasal mucosa coincide with the rise in serum concentration of female sex hormones with gestational age. 5

Ellegard and Karisson study concluded that pregnancy induced rhinitis affects $20 \%$ of pregnancies.

It is also suggested that nasal congestion in the mother may have a potential risk factor for proper development and growth of the foetus by causing gradual decrease in oxygenation. Therefore, early diagnosis and treatment is also important for the well-being of the foetus. ${ }^{3}$ Acute rhinitis and sinusitis with associated fever were other causes for the nasal congestion, rhinorrhoea and headache. Headache in pregnancy is common but is under reported. In our study only 16 patients presented with headache. Rhinitis, sinusitis being the main causes, migraine and cluster headache were reported as well. Headache in pregnancy is to be carefully evaluated as it might be a red flag sign of pre-eclampsia.

Decreased smell perception in pregnancy is said to be due to increased estradiol steroid and decreased ciliary action of the nasal mucosa. ${ }^{5}$

\section{Throat}

Throat symptoms were reported less compared to nose and ears. Only $18 \%$ of the study population presented with one of the symptoms, i.e., throat pain, difficulty in swallowing, foreign body sensation, itching in throat and change in voice. $7.3 \%$ accounted these symptoms to GERD or its variant LPR. This was mainly present during second and third trimester.

\section{The Pathophysiology is related to-}

1. Decrease in lower oesophageal sphincter tone due to increased circulating levels of oestrogen and progesterone.

2. An increase in intra-abdominal pressure secondary to effects of gravid uterus. ${ }^{6}$

Dysphonia was observed only in two patients in whom, oedema of bilateral vocal cords was observed with normal mobility.

\section{Facial Paralysis}

The incidence of idiopathic facial palsy or Bell's palsy is higher in pregnancy. The pregnant women have a 3.3 times increased risk of developing this palsy which is more during the third trimester of pregnancy ${ }^{7}$. This increased risk is due to oedema of facial nerve and surrounding tissues due to increased interstitial fluid volume, which causes compression of the nerve and ischemia of the fallopian canal ". The other major hypothesis is viral, as the gestational immunosuppression induced by rise in cortisol levels, lead to reactivation of a latent herpes simplex virus ${ }^{7}$. Idiopathic facial palsy/Bell's palsy was reported in 3 patients in our study. There was no preponderance to any trimester. It affected patients equally in all trimesters. Bell's palsy causes distress in the patients as it causes a cosmetic and functional defect.

\section{CONCLUSION}

In our study, of all ENT symptoms evaluated, nasal block was the main symptom, with a significant occurrence in the third trimester which was mainly due to Rhinitis of Pregnancy. In the ear, otomycosis was the main aetiology for a variety of ear symptoms such as earache, ear block, ear fullness and itching. GERD and or LPR was the cause for throat symptoms such as throat pain, itching and difficulty in swallowing. In relation to the trimesters, only these three symptoms had significant preponderance, i.e., earache was common in first trimester ( $p$ value $=0.041$ ), nasal block was more common in $3^{\text {rd }}$ trimester ( $\mathrm{p}$ value $=0.014$ ) and throat pain was more common in second trimester ( $p$ value $=0.046$ ) .

We would like to conclude that otorhinolaryngology symptoms in pregnancy are not uncommon. Otorhinolaryngology symptoms might not pose a threat to pregnancy, but it can affect the quality of life during the same. Hence, more studies are to be done regarding ENT symptoms in pregnancy and its treatment. 


\section{REFERENCES}

[1] Sennaroglu G, Belgin E. Audiological findings in pregnancy. J Laryngol Otol 2001;115(8):617-21.

[2] Bhagat DR, Chowdhary A, Verma S, et al. Physiological changes in ENT during pregnancy. Ind J Otolaryngo Head and Neck Surg 2006;58(3):268-70.

[3] Thellin 0, Heinen E. Pregnancy and the immune system: between tolerance and rejection. Toxicology 2003;185(3):179-84.

[4] Havas TE, Wu RM. ENT complaints in pregnancy. O\&G Magazine 2012;14(4):50.
[5] Philpott CM, Conboy P, Al-Azzawi F, et al. Nasal physiological changes during pregnancy. Clin Otolaryngol Allied Sci 2004;29(4):343-51.

[6] Baron TH, Richter JE. Gastroesophageal reflux disease in pregnancy. Gastroenterol Clin North Am 1992;21(4):777-91.

[7] Falco NA, Eriksson E. Idiopathic facial palsy in pregnancy and puerperium. Surgery Gynaecol Obstet 1989;169(4):337-40. 